\title{
Effects of seismic activity on the fluorescence signal of groundwater
}

\author{
Matthias Mäder ${ }^{1}$, Fanny Leuenberger ${ }^{2}$ and Werner Balderer ${ }^{3^{*}}$ (D)
}

\begin{abstract}
Background: Peroxy defects in minerals from stressed igneous and high grade metamorphic rocks release charge carriers which are highly mobile. This process is proposed as the main cause of observed pre-seismic phenomena such as infrared emission on the surface, positive air ionization or a change of ground water chemistry. The primary changes in groundwater chemistry is caused through an increase in oxidation on the rock-water-boundary. This can be detected by observing a rise in fluorescence due to an $\mathrm{O}$ addition on an aromatic ring which can change a substance. For example a terephthalate can change from a non-fluorescent to a partially fluorescent compound due to $\mathrm{O}$ additions.

Results: In this paper we present results of groundwater fluorescence monitoring over a period of approximately three months. We observe distinct wavelengths with an on-line flow-through fluorometer in two different thermal springs in the northern part of Switzerland. We will also show that fluorescent intensities fluctuate widely and display clear increases and sharp rapid drops. During the measuring period many smaller earthquakes with a magnitude between 1.0 and 2.6 occurred close to the measuring stations but a strong earthquake was absent. Nevertheless, an increase in fluorescent intensity was measured in both springs prior to a magnitude 2.2 earthquake. After this seismic event the fluorescent intensities suddenly decreased.
\end{abstract}

Conclusions: The presented results comply with the anticipated theoretical considerations.

Keywords: Peroxy defects, Positive holes, Groundwater, Monitoring fluorescence, Seismic activity, Earthquake precursor

\section{Background}

Forecasting earthquakes has attracted considerable attention recently but thus far there is no suitable explanation as to why non-seismic pre-earthquake manifestations exist. Friedemann Freund proposed the theory that the existence of peroxy defects and positive holes in rocks explained these phenomena and so attempted to lay the scientific basis for the cause of many earthquake precursor signals (Freund, 2006). Freund's theory was later expanded to show how the redox conversion of $\mathrm{OH}^{-}$pairs into peroxy anions and molecular $\mathrm{H}_{2}$ works. Freund showed that by maintaining thermodynamic rules (Freund and Freund, 2015).

Pre-seismic events such as thermal infrared emissions, surface temperature anomalies, radon irregularities and changes in physical and chemical properties of

\footnotetext{
* Correspondence: werner.balderer@erdw.ethz.ch

${ }^{3}$ Geological Institute, ETH Zürich, Sonneggstrasse 5, 8092 Zürich, Switzerland Full list of author information is available at the end of the article
}

groundwater prior to major earthquakes have been reported (Tramutoli et al., 2005; Piroddi et al., 2014; Guangmeng, 2008, Ouzounov et al., 2006; Singh et al., 2016; Biagi et al., 2000; Fidani et al., 2017). Anomalies in $\mathrm{pH}$, conductivity or variations in ion content of groundwater can be explained through the interaction between positive holes and water (Grant et al., 2011). Within stressed rock peroxy links can break. When this occurs an electron next to $\mathrm{O}^{2-}$ anion is transferred onto the broken peroxy link. The electron donor changes its valence from 2- to 1- (Balk et al., 2009). An $\mathrm{O}^{-}$surrounded by $\mathrm{O}^{2-}$ (termed as "positive hole") is an oxygen anion defect by 1 electron in the $\mathrm{O}^{2-}$ anion sublattice and acts as a charge carrier h. (Griscom, 2011; Freund and Freund, 2015). These charge carriers flow out of stressed rock regions and into less stressed rock regions where they can interact with groundwater.

The charge carriers are chemically seen highly oxidizing $\mathrm{O}^{-}$radicals. These radicals can oxidize water to 
hydrogen peroxide $\mathrm{H}_{2} \mathrm{O}_{2}$ on the rock-water boundary and partially oxidize organic compounds dissolved in the groundwater. The partial oxidation of organic compounds can cause a shift in fluorescent intensity and in the fluorescent spectrum (Grant et al., 2011). An example is the oxidation of terephthalates where an $\mathrm{O}^{-}$radical is added to the aromatic ring which leads to a detectable change in the fluorescent spectrum (Saran and Summer, 1999). However, exactly which dissolved organic substances are present in the oxidation reaction involving the charge carriers and their change in the fluorescent spectrum is not yet known.

The reaction between the charge carriers and the groundwater showing an increase in the fluorescent intensity signal could provide evidence of increasing tectonic stress rates in the subsurface.

A limited number of studies have monitored fluorescent intensities using long interval measurements with a flow-through fluorometer. Fluorescent intensity changes were first observed in 1999 using synchronous scans of fluorescent spectra in water samples taken by chance prior to and after a strong earthquake (Balderer and Leuenberger, 2007, Grant, R.A., T. Halliday, W.P. Balderer, F. Leuenberger, M. Newcomer, G. Cyr, F.T. Freund. 2011, Fidani et al., 2017. Our study is one of the first to monitor fluorescent intensities over a time of 11 weeks in two different springs in the northern part of Switzerland. Changes in fluorescent intensities are correlated in our study with the seismic data of nearby stations to deduce potential coincidences. The method of fluorescent monitoring used in our study and the geological and tectonic setting of our chosen physical area in Baden and Rheinfelden Switzerland are explained. Subsequently, the results are presented, discussed and conclusions about the method are drawn.

\section{Method}

A commercially available fluorometer (GUGN-FL30) developed by the University of Neuchatel to detect events of artificial fluorescence tracer tests, was used for the continuous monitoring of fluorescence at both spring sites observed.

An optical system is located inside the flow-through fluorometer. Water flows through a quartz tube within a steel case in this device. It is crucial to maintain continuous water flow in the measurement tool. To achieve this end, the fluorometer was installed at a lower height than the water flow.

Occasional removal of calcareous deposits inside the tube is essential to ensure that measurements were not adversely affected by these deposits. In our study at both spring sites, the calcareous deposits were not significantly large enough due to the limited measuring period. Therefore, the influence of the purgation on the fluorescence measurement was assumed to be insignificant and a correction analysis for the purgation was neglected.

The optical system consists of four different LEDs. Each light source has a specific wavelength. In this case $370 \mathrm{~nm}, 470 \mathrm{~nm}, 525 \mathrm{~nm}$ and $660 \mathrm{~nm}$ were used to excite the fluorescent components in the water. The emission optics are arranged perpendicular to the excitation plains. The emissions of the fluorophores are filtered to determine the wavelength range detected by photodiodes (Schnegg, 2002). The monitored measurement interval of the fluorescence intensity in $\mathrm{mV}$ was $300 \mathrm{~s}$. The schematic concept of the fluorometer is shown in Fig. 1.

A high turbidity (mainly caused by degassing) can adversely influence the intensity of the fluorescent measurements. In the case of the Rheinfelden spring where a high $\mathrm{CO}_{2}$ content exists, a degassing device was

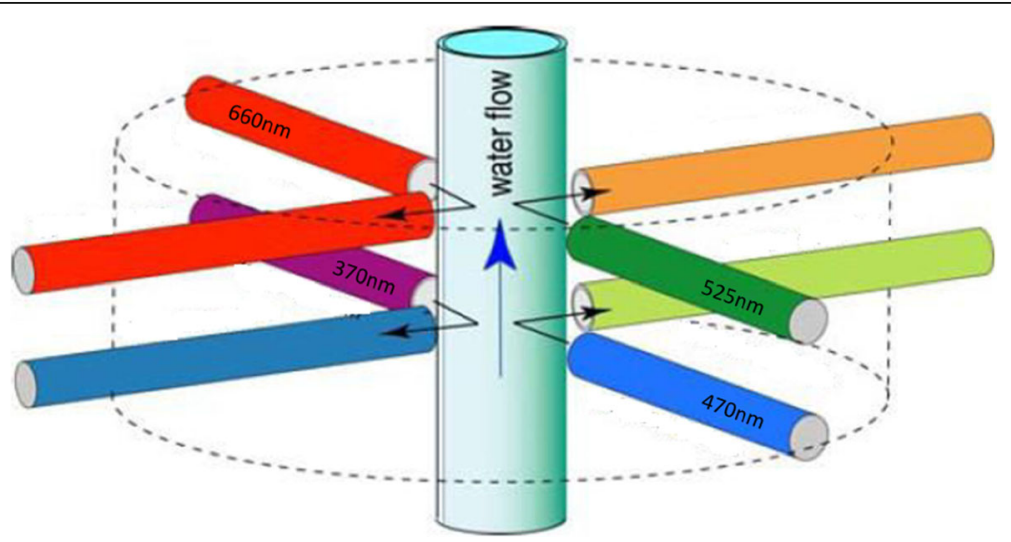

Fig. 1 Schematic functional sketch of the installed flow-through fluorometer of the type GUGN - FL30. The light sources with the specific wavelengths namely, $370 \mathrm{~nm}, 470 \mathrm{~nm}, 525 \mathrm{~nm}$ and $660 \mathrm{~nm}$ and corresponding detector ends are represented together with arrows perpendicular to the main water through flow tube (modified after Schnegg 2002) 
installed to reduce turbidity. Besides degassing and turbidity, a possible mixing of the thermal spring water with a neighbouring aquifer can influence the fluorescence signal. The order of magnitude by which the fluorescence intensity is affected by such a mixing depends on the constituents of the inflowing aquifer. Anthropogenic influxes in the form of chemicals such as cleaning agents from nearby industry or thermal baths resorts could also adversely influence measurements taken.

\section{Geological and tectonic setting of the investigated springs of Baden and Rheinfelden}

The measurements presented here originate from an unused thermal deep well at Rheinfelden (latitude $47.5505^{\circ}$, longitude $7.8058^{\circ}$ ) and from a hot spring in Baden (latitude $47.4808^{\circ}$, longitude $8.3130^{\circ}$ ). The geological overview of Switzerland is presented in Fig. 2 whereas the tectonic setting and the seismicity of the investigated area are presented in Fig. 3.

The Rheinfelden thermal well temperature is $12{ }^{\circ} \mathrm{C}$ with a $\mathrm{pH}$ of 6.6 and a conductivity of $5420 \mu \mathrm{S} / \mathrm{cm}$. This well contains $\mathrm{Na}-\mathrm{Ca}-\mathrm{Cl}-\mathrm{HCO}_{3}-\mathrm{SO}_{4}$ thermal water with a high $\mathrm{CO}_{2}$ content and originates at a depth of $550 \mathrm{~m}$. Geologically it is in late Palaeozoic sediments (Perm, Rotliegendes) below dense evaporitic layers
(Muschelkalk and Keuper) from the early Mesozoic era (Burger, 2009). Rheinfelden is situated in close vicinity to the Rhine Graben-structure, a 300-350 km long rift where the geology and tectonics have been studied in detail (Sissingh, 1998; Becker, 2000; Ustaszewski and Schmid, 2007). The detailed well profile of the Rheinfelden spring is presented by Ryf (1984).

The thermal springs of Baden lie in the "Lägeren" structure where the Limmat eroded into the Muschelkalk layers in the eastern part of the Faltenjura. The Baden hot spring contains fluids originating from the base rock ascending through the evaporites of the middle Muschelkalk layers, along a tectonic fault, which is characterized as the Jura-Overthrust (Burger, 2009; Löw, 1987; Nagra, 2014, Fig. 3.3-2). The aquifer has a piezometric head of $359 \mathrm{~m}$ a.s.l. and is therefore artesian against the local river Limmat (350 $\mathrm{m}$ a.s.l.) and the surrounding groundwater streams (348$357 \mathrm{~m}$ a.s.l.) (Löw, 1987). The Baden spring water with a total mineralization of around $4.5 \mathrm{~g} / \mathrm{l}$ and a conductivity of $5970 \mu \mathrm{S} / \mathrm{cm}$ and is hydro-chemically characterized by $\mathrm{Na}-\mathrm{Ca}-(\mathrm{Mg})-\mathrm{Cl}-\mathrm{SO}_{4}$ type and contains higher amounts of characteristic dissolved gasses, namely $\mathrm{H}_{2} \mathrm{~S}(3.0 \mathrm{mg} / \mathrm{l}), \mathrm{CH}_{4}(<0.3 \mathrm{mg} / \mathrm{l})$ and $\mathrm{CO}_{2}$ (292 mg/l) (Rick, 2007; Högl, 1980). The water has a temperature around $46{ }^{\circ} \mathrm{C}$ and a $\mathrm{pH}$ of 6.6.

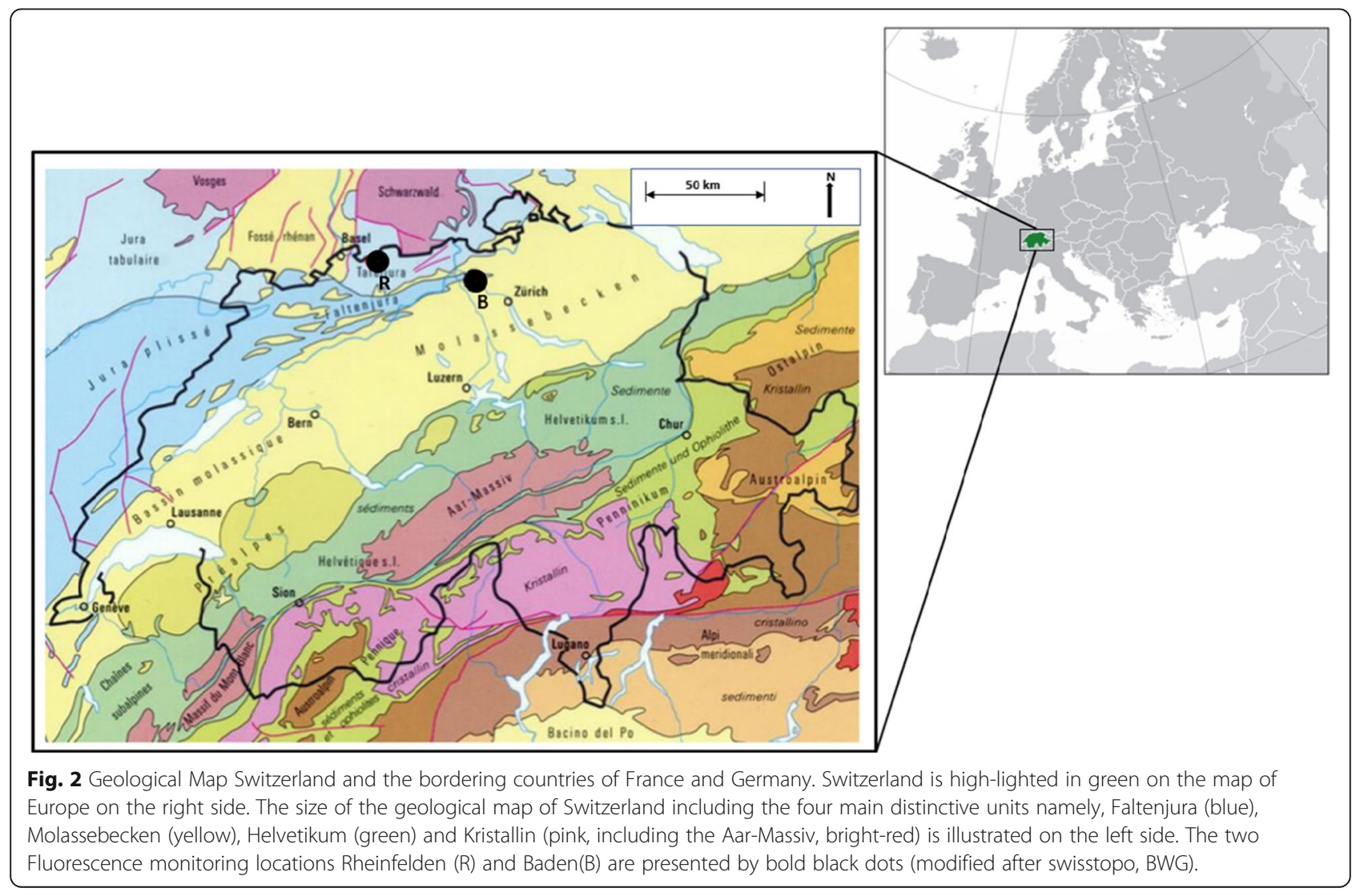




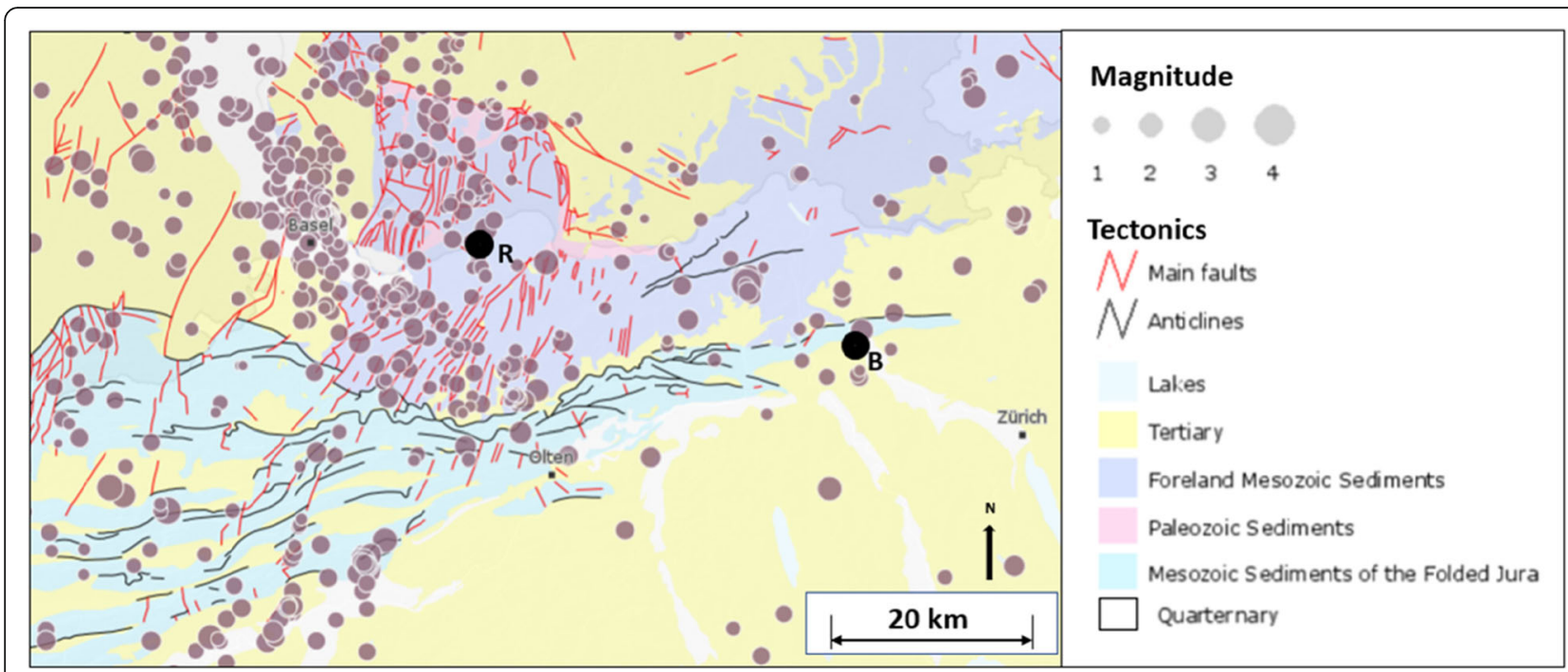

Fig. 3 Map of the area of Northern Switzerland and the bordering countries of France and Germany with represented magnitudes of the main occurring earthquakes. The two Fluorescence monitoring locations Rheinfelden (R) and Baden (B) are indicated with bold blackish dots. The reddish lines represent the main tectonic faults in the nearby area of the measurement locations. The greyish circles illustrate the locations of the registered earthquakes since 2001. The size of the circles corresponds to the magnitude of the earthquakes according to the legend on the right side of the figure (modified after SED)

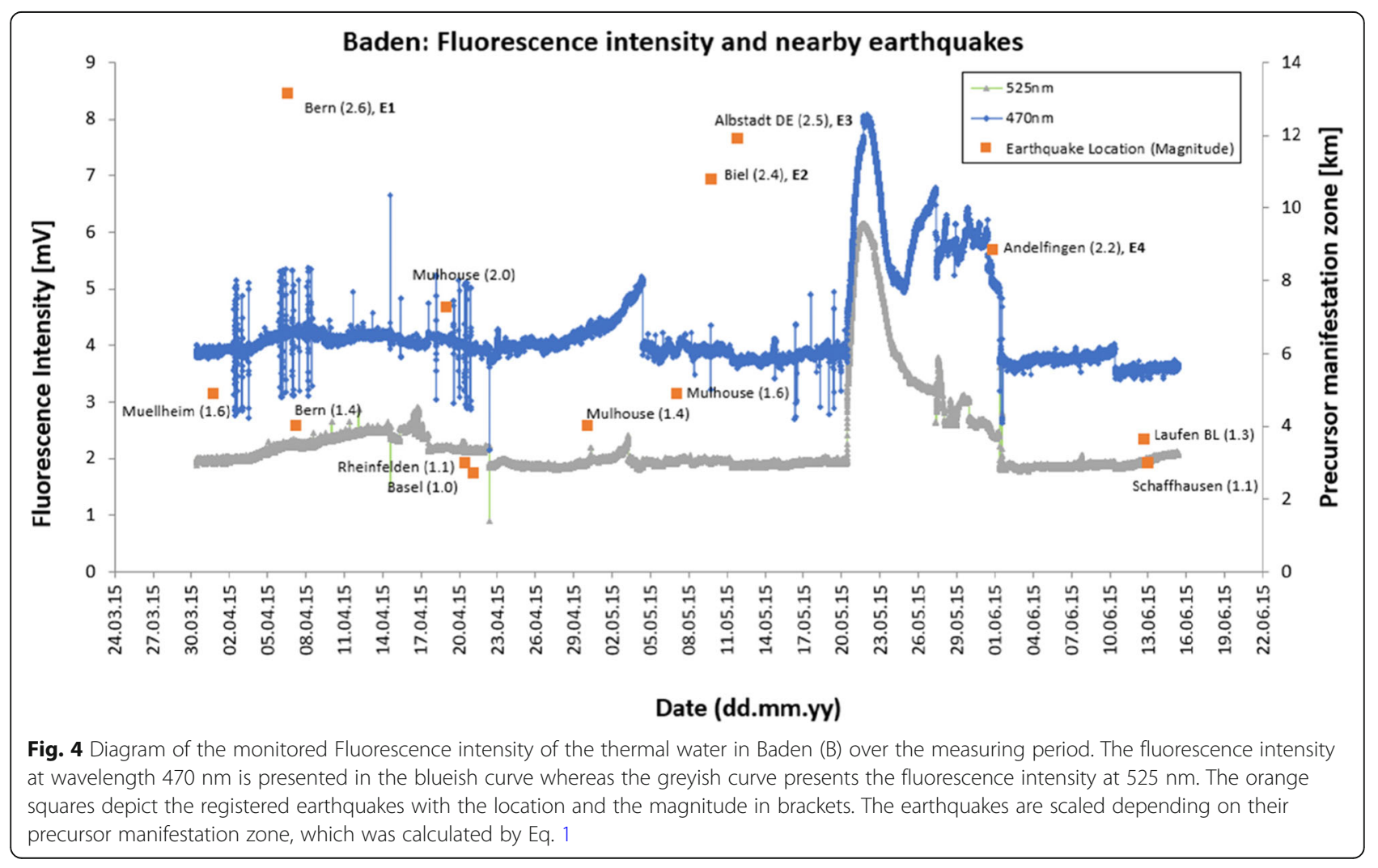




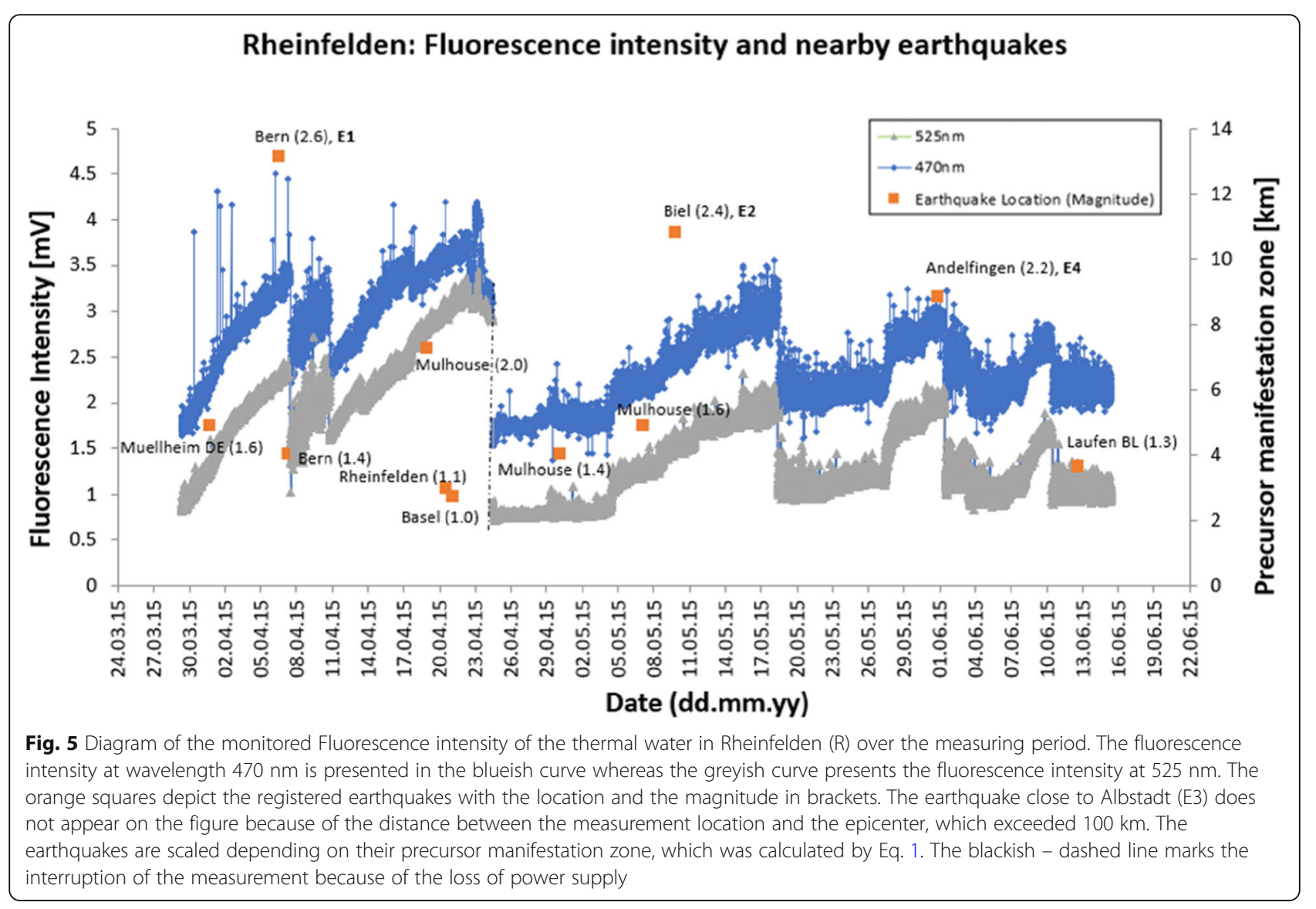

\section{Results}

The following figures (Figs. 4 and 5) show fluorescent intensities over the measured time and the location and magnitude of the earthquakes that occurred. Only earthquakes which had a magnitude 1 or higher and were experienced within a radius of $100 \mathrm{~km}$ from the spring site measurement location were considered. Out of the four possible wavelength sensors only the most significant results are presented. These were using the $470 \mathrm{~nm}$ and $525 \mathrm{~nm}$ signals. The strain $(\varepsilon)$ and strain radius of the nearby registered earthquakes are calculated using the Dobrovolsky relation (Eqs. 1 and 2) (Dobrovolsky et al., 1979).

$$
\begin{aligned}
& 10^{0.43 * \mathrm{M}}=\text { strain radius } \\
& 10^{1.3 * \mathrm{M}-8.19}=\varepsilon
\end{aligned}
$$

The strain radius is the estimated zone around the epicentre of an effective manifestation of precursor deformation and is dependent on the magnitude $M$ of the earthquake (Dobrovolsky et al. 1979). This relation is a very useful approach to obtain a semi-quantitative number for the precursor manifestation zone. This approach assumes that non-mechanical precursors are caused by deformation of the surrounding medium.

The theory states that a possible manifestation of a precursor occurs within the strain radius and can be detected when the monitoring site lies inside this estimated zone. The calculation of the strain combines the impact of the magnitude and the distance to the monitoring site. This result helps predict if a precursor is expected at the measurement site or not. According to Dobrovolsky et al. (1979) lies the monitoring side inside the deformation zone if the determined strain is above $10^{-8}$. However, whether the monitoring site lies inside the strain radius is not that significant when the expected changes in fluorescence intensities are assumed to be caused through the stress activated charge carriers.

It has been demonstrated in lab experiments that these charge carriers are highly mobile and it is assumed that they can propagate far away from the stressed rock region (Freund and Freund, 2015; Scoville et al., 2015). Nevertheless, the strain and the strain radius were calculated to follow the initial scaling approach of earthquake precursors and to get a rough estimation of the extent of the deformation zone. The positive holes are generated in the deformation zone and therefore it is expected that stronger earthquakes with larger 
Table 1 The registered earthquakes during the measuring period with a magnitude higher than 2.0 are listed below with the corresponding geographical coordinates (Lat / Long), magnitude (M) and depth of the earthquakes. E1, E2, E3, E4 are identification numbers for the earthquakes which are mapped in Figs. 4, 5 and 6. The distances between the epicentres and the measurement locations Baden (B) and Rheinfelden (R) were calculated. The strain radius was calculated by means of Eq. 1. Strains at the monitoring site $\mathrm{R}$ and $\mathrm{B}$ are calculated by Eq. 2

\begin{tabular}{|c|c|c|c|c|c|c|c|c|}
\hline Earthquake & Lat / Lon [ ["] & M & Depth [km] & Distance to B [km] & Distance to R [km] & Strain radius [km] & Strain $\varepsilon$ at: B & Strain $\varepsilon$ at: $R$ \\
\hline E1 & $46.90 / 7.42$ & 2.6 & 5.7 & 93.3 & 77.9 & 13.1 & $1.91 * 10^{-11}$ & $3.28^{*} 10^{-11}$ \\
\hline E2 & $47.15 / 7.15$ & 2.4 & 9.8 & 95.0 & 66.5 & 10.8 & $9.93^{*} 10^{-12}$ & $2.89^{*} 10^{-11}$ \\
\hline E3 & 48.24 / 9.05 & 2.5 & 9.6 & 100.0 & $>100$ & 11.9 & $1.15^{*} 10^{-11}$ & $<1.15^{*} 10^{-11}$ \\
\hline E4 & $47.66 / 8.74$ & 2.2 & 7.4 & 37.7 & 71.0 & 8.8 & $8.73^{*} 10^{-11}$ & $1.31^{*} 10^{-11}$ \\
\hline
\end{tabular}

deformation zones tend to activate more charge carriers than weaker ones. Therefore, only earthquakes with magnitude higher than 2.0 were considered for the strain respectively strain radius calculations and as possible detection targets. The four registered earthquakes with a magnitude higher than 2.0 are listed in Table 1 and mapped in Fig. 6. Data and information about registered earthquakes are provided from the SED (Swiss Seismological Service).

\section{Results: Baden}

The measured fluorescence intensity at wavelength of $470 \mathrm{~nm}$ which is shown in Fig. 4 fluctuated widely around $4 \mathrm{mV}$ whereas the intensity at wavelength of $525 \mathrm{~nm}$ fluctuated around $2 \mathrm{mV}$. The measurements sometimes showed dispersions in the fluorescent intensity within a small-time interval. These events were mainly caused by short intervals of high $\mathrm{CO}_{2}$ overpressure and outgassing. The reason behind is the thermal water of the Baden spring is $\mathrm{CO}_{2}$ oversaturated and outgases through pressure decrease with the natural ascendance of the water. This outgassing process does not happen continuously. It is more a periodical process. The measured course of fluorescent signal at $470 \mathrm{~nm}$ shows one gradual increase (April 23th 2015 - May 4th, 2015) of more than $1 \mathrm{mV}$ which is followed by a significant rapid drop. The other obvious event is a significant jump in intensity to $8 \mathrm{mV}$ within 3 days and followed by a wide fluctuation until a significant rapid drop occurred (June 1st, 2015). The fluorescence intensity at wavelength $525 \mathrm{~nm}$ shows a similar but not identical behaviour as the signal at $470 \mathrm{~nm}$. During the survey, many smaller earthquakes within a radius of $100 \mathrm{~km}$ happened. The earthquakes close to Bern (E1) with a magnitude of 2.6

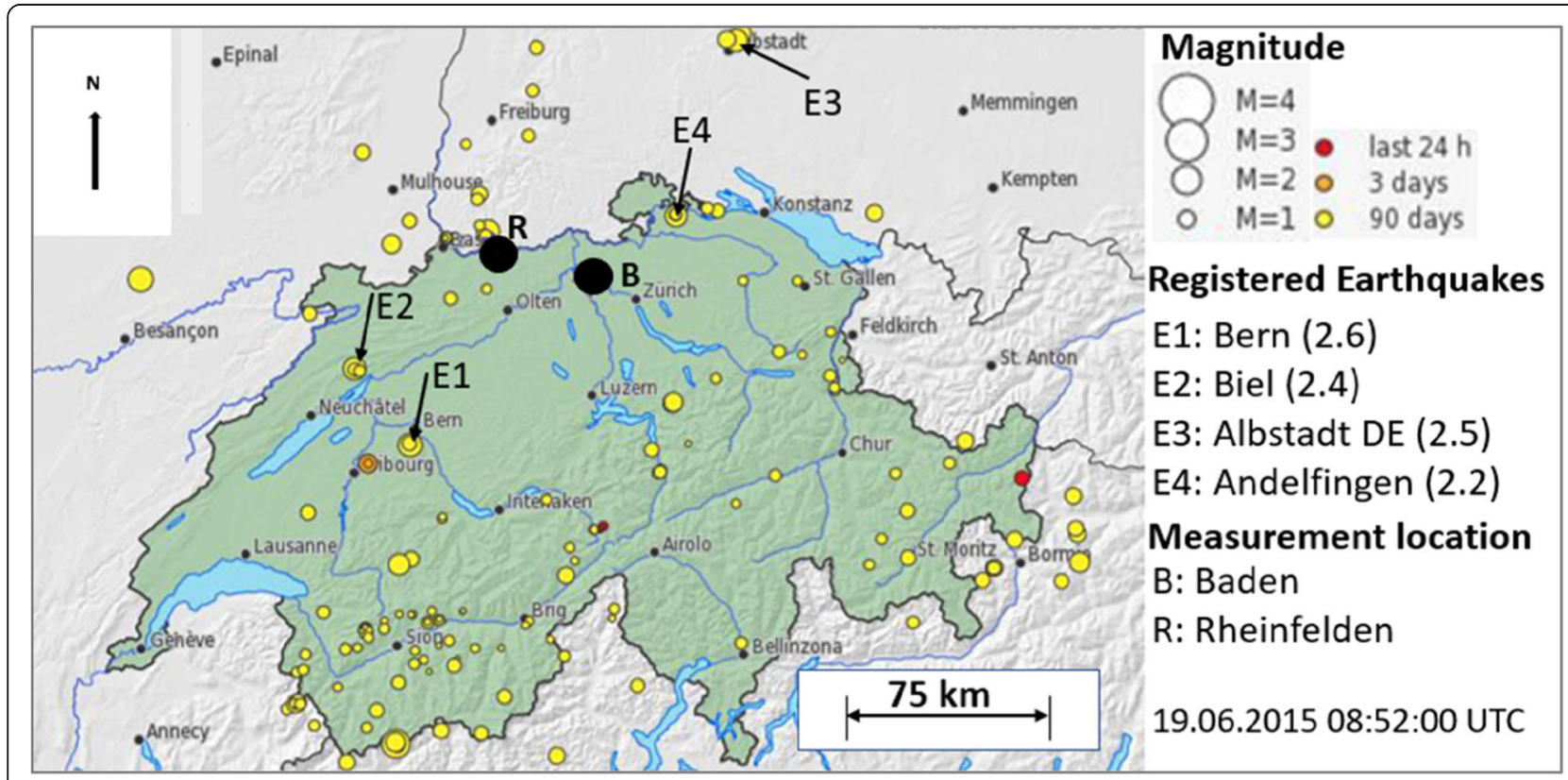

Fig. 6 Map of Switzerland with representation of all the earthquakes, which were registered within a time span of 90 days before the fluorescence monitoring was stopped are highlighted in the map of Switzerland by yellow dots. The size of the circles corresponds to the magnitude of the earthquakes according to the legend on the right side. The location of the earthquakes from Table 1 are highlighted with the blackish arrows. The measurement locations Baden (B) and Rheinfelden (R) are indicated by the bolt blackish dots (modified after SED) 
and Albstadt (E3) with magnitude 2.5 were the strongest but both epicentres were relatively far (E1: $93.3 \mathrm{~km}, \mathrm{E} 3$ : $100.0 \mathrm{~km}$ ) from the measuring station (B) (Table 1, Fig. 6). The seismic event E1 was the strongest earthquake with a corresponding strain radius of $13.1 \mathrm{~km}$. The earthquake from May 31th 2015 around Andelfingen (E4) with magnitude 2.2 lay just $37.7 \mathrm{~km}$ away from the station $\mathrm{B}$ and is therefore of most interest for our studies. All calculated strains at monitoring site $\mathrm{B}$ are below the threshold of $10^{-}$ 8 and lie therefore outside the deformation zone.

\section{Results: Rheinfelden}

The monitored fluorescence intensity curves of Rheinfelden, measured at wavelengths $470 \mathrm{~nm}$ and $525 \mathrm{~nm}$ are presented in Fig. 5. The intensity at $470 \mathrm{~nm}$ fluctuated widely with a range from $1.6 \mathrm{mV}$ to $4.1 \mathrm{mV}$. The fluorescence signal at $525 \mathrm{~nm}$ shows an almost identical behaviour as the signal at $470 \mathrm{~nm}$ but with lower fluorescent intensities. Despite an installed outgassing device, the very high $\mathrm{CO}_{2}$ content of the Rheinfelden spring caused a greater dispersion of the signals than in the Baden measurements. The beginning of the measuring period is dominated by a rapid increase from $1.8 \mathrm{mV}$ to $4.1 \mathrm{mV}$ with two main rapid drops, which interrupts the gradual increase in fluorescence intensity at $470 \mathrm{~nm}$. Another significant drop (April 24th, 2015) happened due to a sudden power loss to the fluorometer which is indicated through the blackish dashed line in Fig. 5. This sudden drop in fluorescence intensity at both wavelengths occurred because of the shut-down (power loss) of the fluorometer and must be negated for interpretation. After this interruption, the continuation shows a considerable steady increase at both distinctive wavelengths until a sudden drop (May 18th, 2015) occurred. The last parts of the curve are dominated by two rapid increases, both of which are followed by rapid drops (Fig. 6). Out of the 4 earthquakes from Table 1, the earthquake close to Biel (E2) with a magnitude of 2.4 and a corresponding strain radius of $10.8 \mathrm{~km}$ was the closest earthquake $(66.5 \mathrm{~km})$ to the Rheinfelden measurement location ( $R$ ). However, all the strains at monitoring site $\mathrm{R}$ lie below the postulated threshold.

\section{Discussion}

The fluorescence intensities vary at moderate magnitudes at both spring sites over the whole monitoring period. Intervals with stable intensity values are scarce. The main trend of the observed fluorescence monitoring is dominated by several increases which are followed by sudden decreases in fluorescent intensities.

Intensified tectonic stresses in the subsurface leads to an increase of stress generated charge carriers which flow out of the stressed rock region into the less stressed rock regions. When more charge carriers are generated, the oxidation on the rock-water boundary is increased and the fluorescence intensity rises. The expected shape and the duration of the increasing fluorescence intensity curve prior to an earthquake is not known yet but it is assumed that it is most likely variable.

The theory assumes that the higher the magnitude of an earthquake is, the higher the impact of the fluorescent signal in the measured groundwater will be. Because of the lack of strong seismicity in close vicinity to the monitoring stations during the measuring period it is difficult to determine correlations between changes in fluorescence and earthquakes.

The calculated strains of the earthquakes E1 - E4 for both monitoring sites are much smaller than the postulated $10^{-8}$. This means that these four earthquakes should not manifest themselves at the monitoring site using the Dobrovolsky approach. However, all the four earthquakes (E1 - E4) happened at very shallow depths and it should be considered that the stress generated charge carriers can flow much further than the strain radius estimates.

At the Rheinfelden spring site the fluorescence signal steadily increased until the earthquake (E1) with a magnitude of 2.6 close to Bern happened. Subsequently the fluorescence intensity rapidly dropped after the registered earthquake. However, this phenomenon cannot be clearly identified as a coherence between the fluorescence signal and the earthquake because of the low magnitude and the large distance to the measuring station (R). Additionally, on April 11th, 2015 a similar rapid drop in fluorescence intensity occurred but in absence of an earthquake. The registered earthquakes close to Biel (E2) and Albstadt (E3) do not show any possible changes to the fluorescence signals at both spring sites. The earthquake E3 is not reflected in Fig. 5 because of the distance, which exceeded the maximum distance of $100 \mathrm{~km}$.

Prior to the earthquake (E4) with a magnitude of 2.2 close to Andelfingen, an increase in fluorescence intensity was measured at both spring sites. Moreover, the fluorescence signals suddenly dropped immediately after the earthquake (E4) occurred. The increase and sudden decrease of the fluorescence intensity was more pronounced at the Baden spring (B) than in Rheinfelden (R). The reason behind this could be found in the shorter distance from the epicentre to the measuring station in Baden compared to the distance to Rheinfelden. This recorded specific change in fluorescence intensity is quite remarkable because of its occurrence at both spring sites prior to and after the earthquake. Such an event in fluorescence change would be expected and would be consistent with the theory of the release of stress generated charge carriers which cause an oxidation 
of the groundwater. However, that this change in the fluorescence signal can be identified because of increased and diminished tectonic stresses in the subsurface is beyond the current understanding of the phenomena. Nevertheless, this method could be a useful tool in future earthquake forecast because of its sensitivity to a wide catchment area which depends on the extent of the aquifer and its flowrate. Furthermore, the modest methodology and the straightforward installation and maintenance of the fluorometer is another point in favour of this monitoring method. The limitation of the method lies in the strong influence of outgassing and turbidity on the fluorescence signal of the groundwater. External factors which influence the fluorescence intensity besides aquifer mixing and anthropogenic influxes are not yet known and further research is needed.

\section{Conclusion}

The results presented clearly show the variability of fluorescence intensity of ground water at the distinct wavelengths. Furthermore, the results support a possible link between the stress generated charge carriers caused by tectonic processes leading to earthquakes and their interaction with the investigated thermal water. However, these preliminary results should be confirmed by further monitoring of fluorescence of groundwater at alternate groundwater sites in tectonically more active areas.

The selection of appropriate springs or wells is crucial. Most suited for in-situ fluorescence monitoring are sites with artesian groundwater outflow such as the investigated Baden spring and the Rheinfelden borehole. Groundwater of pumped wells are more affected by disturbances due to pumping intervals and non-steady state situations in respect to considering hydraulic head and degassing processes.

Furthermore, the monitoring period should be extended to enhance the probability of earthquake occurrences and to allow long term analysis. Fluorometers with a wider wavelength spectrum and an advanced sensitivity would be a further asset. This would allow the wavelength spectrum to be tuned to the most significant wavelengths in terms of changes in fluorescent intensities as an earthquake precursor. Furthermore, a wider wavelength spectrum could provide further information about possible shifts in fluorescence spectra. Beyond that, further investigations into the oxidation process of dissolved organic compounds in the ground water should be done in order to improve the understanding of the phenomena.

\section{Abbreviations}

B: Measuring station in Baden; E1 -E4: Earthquake identification numbers; GUGN-FL30: type of fluorometer developed by the University of Neuchatel; LED: Light emitting diode; M: Magnitude; R: Measuring station in Rheinfelden; $\varepsilon$ : strain of the nearby registered earthquakes calculated using the Dobrovolsky relation $\left[10 \rrbracket \wedge\left(0.43^{*} \mathrm{M}\right)\right.$ strain radius of the nearby registered earthquakes are calculated using the Dobrovolsky relation

\begin{abstract}
Acknowledgements
Very special thanks goes out to Mr. Kost and the RehaClinic team Baden and to Mr. Franz Resnig, Thermal spa foundation. Dr. Barbara Reyes-Trüssel, Geophysicist at EBERHARD \& Partner AG for providing the possibility to use the deep borehole at Rheinfelden for on-line measurements, Mr. Lehman and the city of Rheinfelden for the support they provided us during the survey.
\end{abstract}

\section{Funding}

This published research was not subject of any special funding and results from the normal program of education studies of ETH in the frame of Earth Science Department. The applied instruments are property of the Geological Institute, Engineering Geology and of the hydrological section of the Swiss Federal Institute for Forest.

\section{Availability of data and materials}

The fluorescence datasets supporting the conclusions of this article are included within the article. The information on the registered earthquakes is available in the repository of the SED: http://www.seismo.ethz.ch

The information on the flow-through fluorometer is available on: http:// www.albillia.com

\section{Authors' contributions}

Dr. WB was as Senior lecturer supervisor of the presented study and CoAuthor and organized the availability of investigated test sites, setup of instruments, instruction of maintenance and exploitation and interpretation of fluorescence monitoring. MM made the fluorometer measurements exploitation, and interpretation of the results and studied the relation to the occurring earthquakes of the related areas in the frame of his thesis of Bachelor of Earth Sciences degree from ETH Zurich. Dr. FL was responsible for the lab measurements and the fluorescence synchronous scan spectra measurements on additional water samples of both investigated thermal water monitoring sites. All authors read and approved the final manuscript.

\section{Authors' information}

Werner Balderer was from 1986 to 2010 Lecturer of Isotope Hydrogeology, and General Hydrogeology at ETH Zurich, his research interests include Mineral and Thermal water and research on Natural fluorescence of groundwater as proxi of tectonic activity.

Matthias Mäder holds a Bachelor of Earth Sciences degree from ETH Zurich with a major in geophysics.

Matthias is a current Master student in Petroleum Engineering \& Geosciences at TU Delft, Netherlands. His research interests includes the understanding of pre-earthquake phenomena and petroleum geology.

\section{Ethics approval and consent to participate}

'Not applicable'.

\section{Consent for publication}

According to the ETH Zurich the bachelor thesis and its publication belongs to the personal property right of the students of Bachelor degree from ETH Zurich.

\section{Competing interests}

All the authors have no competing interests in the research subject of this publication. No one is working in industries or has ties to such in the domain of the published research. Therefore, no financial and non-financial competing interests exist.

\section{Publisher's Note}

Springer Nature remains neutral with regard to jurisdictional claims in published maps and institutional affiliations.

\section{Author details}

'Department of Geoscience, TU Delft, Stevinweg 1, 2628 CN Delft, Netherlands. ${ }^{2}$ Geological Institute, Engineering Geology, ETH Zürich, Sonneggstrasse 5, 8092 Zürich, Switzerland. ${ }^{3}$ Geological Institute, ETH Zürich, Sonneggstrasse 5, 8092 Zürich, Switzerland. 
Received: 26 February 2017 Accepted: 4 July 2018

Published online: 11 July 2018

\section{References}

Balderer, W., and F. Leuenberger. 2007. Observation of Fluorescence Spectra of Groundwater in Areas of Tectonic Activity: Could it act as a Precursor of Earthquakes? In Geochemical Precursors for Earthquakes, ed. Prasanta Sen and Nisith K. Das. Macmillan India Ltd. ISBN 10: 0230-63262-9, ISBN 13: 918-02)063262-9.

Balk, M., M. Bose, E. Gözen, D.A. Rogoff, L.J. Rothschild, and F.T. Freund. 2009. Oxidation of water to hydrogen peroxide at the rock-water interface due to stress-activated electric currents in rocks. Earth and Planetary Science Letters 283: 87-92.

Becker, A. 2000. The Jura Mountains - An active foreland fold-and-thrust belt? Tectonophysics 321: 381-406.

Biagi, P.F., A. Ermini, S.P. Kingsley, Y.M. Khatkevich, and E.I. Gordeev. 2000. Groundwater ion content precursors of strong earthquakes in Kamchatka (Russia). Pure and Applied Geophysics 157: 1359-1377.

Burger, H. 2009. Vorkommen, Nutzung und Schutz von Thermalwässern und Mineralwässern im Kanton Aargau: eine Übersicht. Swiss Bull Angew Geol 14/1 +2: 13-27.

Dobrovolsky, I.P., S.I. Zubkov, and V.I. Miachkin. 1979. Estimation of the size of earthquake preparation zones. Pure and Applied Geophysics 117 (5): 10251044.

Fidani, C., W. Balderer, and F. Leuenberger. 2017. The possible influences of the 2012 Modena earthquake on the fluorescence spectra of bottled mineral water. Hydrol Curr Res 8: 288.

Freund, F.T., and M.M. Freund. 2015. Paradox of peroxy defects and positive holes in rocks. Part I: Effect of temperature. J Asian Earth Sci 114: 373-383.

Freund, F.T., A. Takeuchi, and B.W.S. Lau. 2006. Electric currents streaming out of stressed igneous rocks - A step toward understanding pre-earthquake low frequency emissions. Physics and Chemistry of the Earth 31: 389-396.

Grant, R.A., T. Halliday, W.P. Balderer, F. Leuenberger, M. Newcomer, G. Cyr, and F. T. Freund. 2011. Ground water chemistry changes before major earthquakes and possible effects on animals. Int J Environ Res Public Health 8: 1936-1956.

Griscom, D.L. 2011. Trapped-electron centers in pure and doped glassy silica: A review and synthesis. J Non-Cryst Solids 357: 1945-1962.

Guangmeng, G. 2008. Studying thermal anomaly before earthquake with NCEP data. Int Arch Photogramm Remote Sens Spat Inf Sci 35 (1): 295-298.

Högl, O. 1980. Die Mineral- und Heilquellen der Schweiz, Verlag Paul Haupt, Bern, Stuttgart.

Löw, S. 1987. Die Thermalquellen von Baden: Eine geologische hydrogeologische Einführung. Bull. Ver. Schweiz. Petroleum - Geol. u. -ing. 53 (125): 15-18.

Nagra, 2014. Geologische Langzeitentwicklung Geologische Grundlagen SGT Etappe 2: Vorschlag weiter zu untersuchender geologischer Standortgebiete mit zugehörigen Standortarealen für die Oberflächenanlage, Dossier III, Nagra Technischer Bericht 14-02, Dezember 2014, www.nagra.ch

Ouzounov, D., N. Brant, T. Logan, S. Pulinets, and P. Taylor. 2006. Satellite thermal IR phenomena associated with some of the major earthquakes in 1999-2003. Phys Chem Earth 31: 154-163.

Piroddi, L., G. Ranieri, F. Freund, and A. Trogu. 2014. Geology, tectonics and topography underlined by L'Aquila earthquake TIR precursors. Geophys J Int 197: 1532-1536.

Rick, B. 2007. Von heissen Quellen und Baugruben. Umwelt Aargau 36: 23-30.

Ryf, W. 1984. Thermalwasserbohrung 1983 Engerfeld, Rheinfelden. Rheinfelder Neujahrsblätter 1984: 43-52.

Saran, M., and K.H. Summer. 1999. Assaying for hydroxyl radicals: Hydroxylated terephtalate is a superior fluorescence marker than hydroxylated benzoate. Free Radic Res 31: 429-436.

Schnegg, P.A. 2002. An inexpensive field fluorometer for hydrogeological tracer tests with three tracers and turbidity measurements. In XXII IAH \& ALHSUD Congress Groundwater and Human Development, 1484-1488. Mar del Plata: Balkema.

Scoville, J., J. Sornette, and F.T. Freund. 2015. Paradox of peroxy defects and positive holes in rocks part II: Outflow of electric currents from stressed rocks. Journal of Asian Earth Sciences 114: 338-351.

SED Schweizerischer Erdbebendienst. 2015. seismic data, Switzerland: http:// www.seismo.ethz.ch/

Singh, S., H.P. Jaishi, R.P. Tiwari, and R.C. Tiwari. 2016. A study of variation in soil gas concentration associated with earthquakes near indo-Burma subduction zone. Geoenviron Disaster 3: 22.
Sissingh, W. 1998. Comparative tertiary stratigraphy of the Rhine graben, Bresse graben and Molasse Basin: Correlation of alpine foreland events. Tectonophysics 300: 249-284.

Tramutoli, V., V. Cuomo, C. Filizzola, N. Pergola, and C. Pietrapertosa. 2005. Assessing the potential of thermal infrared satellite surveys for monitoring seismically active areas: The case of Kocaeli (Izmit) earthquake, august 17, 1999. Remote Sens Environ 96: 409-426.

Ustaszewski, K., and S.M. Schmid. 2007. Latest Pliocene to recent thick-skinned tectonics at the upper Rhine graben - Jura Mountains junction. Swiss $J$ Geosci 100: 293-312.

\section{Submit your manuscript to a SpringerOpen ${ }^{\circ}$ journal and benefit from:}

- Convenient online submission

- Rigorous peer review

- Open access: articles freely available online

- High visibility within the field

- Retaining the copyright to your article

Submit your next manuscript at $\gg$ springeropen.com 